\title{
РАСПРОСТРАНЕННОСТЬ КИШЕЧНЫХ ПАРАЗИТОЗОВ У ВИЧ-ПОЗИТИВНЫХ ПАЦИЕНТОВ
}

\author{
${ }^{1}$ Д.мед.н. Шагинян В. Р., ${ }^{1}$ К.мед.н. Данько О. П., ${ }^{1}$ Антоняк С. Н., \\ ${ }^{2}$ Казека В. Г., ${ }^{2}$ Федоренко С. В., \\ ${ }^{1}$ ГУ «Институт эпидемиологии и инфекиионных болезней им. Л.В. Громамевского НАМН \\ Украиньл», Украина, Киев, \\ ${ }^{2}$ Городская клиническая больнииа № 5, Украина, Киев
}

DOI: https://doi.org/10.31435/rsglobal_sr/31072019/6611

\section{ARTICLE INFO}

Received 12 May 2019

Accepted 04 July 2019

Published 31 July 2019

\section{KEYWORDS}

HIV;

Intestinal parasites;

CD4 counts;

viral load of HIV;

ART;

Ukraine.

\begin{abstract}
A cross-sectional study among people living with HIV (PLHIV), who are naive and who are on antiretroviral treatment (ART) was conducted in Kyiv, Ukraine from January 2017 to June 2019. In 200 samples of feces from PLHIV were detection intestinal parasites and helminthes. Also in all patients was measure of CD4 T cells by flow cytometry technique and the viral load of HIV (HIV VL) by reverse transcription and polymerase chain reaction, sensitivity of test -40 copies HIV RNA / ml. The study shows high prevalence of intestinal parasitic in population of PLHIV - 30,0\%. The most prevalent parasites were Cryptosporidium (10,5\%), Ascaris lumbricoides (1,5\%), G. lamblia (0,5\%). Opportunistic protozoans (B. Hominis) were found in $15.5 \%$ of PLHIV. Among PLHIV with intestinal parasites severe immunosuppression $(<200 \mathrm{CD} 4$ cells $/ \mathrm{ml})$ were more common $(66.7 \%)$ than among PLHIV without intestinal parasites (45.7\%); patients with undetectable HIV VL (35.0\%), patients receiving ART for more than 6 months $(28.3 \%)$ were less common (55.7\% and $54.3 \%$ respectively). In all cases $\mathrm{P}$ value was less than 0.05 . Our data show that detection even opportunistic intestinal protozoans in PLHIV can be used as a marker of immune suppression and HIV replication activity, and confirms the importance of parasitological surveillance in this group of patients.
\end{abstract}

Citation: Shahinian V. R., Danko O. P., Antonyak C. N., Kazeka V. G., Fedorenko C. V. (2019) Prevalence of Enteric Parasitic Among People Living with Hiv. Science Review. 6(23). doi: 10.31435/rsglobal_sr/31072019/6611

Copyright: (C) 2019 Shahinian V. R., Danko O. P., Antonyak C. N., Kazeka V. G., Fedorenko C. V. This is an open-access article distributed under the terms of the Creative Commons Attribution License (CC BY). The use, distribution or reproduction in other forums is permitted, provided the original author(s) or licensor are credited and that the original publication in this journal is cited, in accordance with accepted academic practice. No use, distribution or reproduction is permitted which does not comply with these terms.

Введение. Примерно 30-60\% людей, живущих с ВИЧ (ЛЖВ) в развитых странах и 90\% в развивающихся страдают диареей [1], нередко обусловленной кишечными паразитами. Известно, что риск возникновение паразитарных инвазий, как и других кишечных инфекций, в первую очередь связан с несоблюдением санитарно-гигиенических норм, ограниченным доступом к воде, жарким климатом. Регионы с высоким уровнем распространенности ВИЧ-инфекции в большинстве своем, также являются зонами риска по распространенности кишечных инфекций и инвазий поэтому наибольшая частота ко-инфекций ВИЧ+паразитозы отмечается в странах Африканского континента, в основном в субэкваториальной Африке. Вероятно, по этой причине большинство работ, посвященных изучению кишечных паразитозов у ЛЖВ, было проведено в этом регионе [2, 3, 4].

Наиболее распространенным среди ЛЖВ паразитозом является криптоспоридиоз [5,6]. Поскольку иммунодефицитные состояния повышают риск развития клинических проявлений при инфекциях и инвазиях, вызванных условно патогенными паразитами, у ЛЖВ часто выявляют опортунистических паразитов, которые являются причиной кишечных расстройств, 
анемии, персистирующей диареи и даже смерти пациентов. По данным большинства исследователей, кишечные паразитозы отмечают у ЛЖВ с низким количеством CD4 T клеток ( $<350$ кл/мкл). В то же время, Taye B. et al. [7] не установили корреляции между уровнем CD4 и частотой выявления кишечных паразитов. Несмотря на практически однозначные данные, полученные разными авторами $[8,9,10]$ о позитивном влиянии антиретровирусной терапии (АРТ) на инвазированность кишечными паразитами ЛЖВ, в исследовании, проведенном в Камеруне была показана высокая распространенность кишечных паразитов у ЛЖВ с количеством CD4 <200 кл/мл, не зависимо от проведения АРТ [11]. Анализ данных литературы свидетельствует, что спектр возбудителей кишечных паразитозов и их распространенность среди ЛЖВ варьирует в различных странах, зависит от факторов внешней среды, природных и социальных условий. Требует углубленного изучения влияние степени иммуносупрессии, получение пациентами АРТ на распространенность кишечных паразитозов. В доступной литературе мы не нашли данных о таких работах, проведенных в европейском регионе.

Цель работы изучить распространенность кишечных паразитов у людей, живущих с ВИЧ, в зависимости от количества CD4 Т клеток, уровня вирусной нагрузки ВИЧ и проведения AРT-терапии.

Материалы и методы. Проведено кросс-секционное исследование в отделениях ВИЧинфекции на базе клиники Института эпидемиологии и инфекционных болезней НАМН Украины и городской клинической больницы № 5 (г. Киев). В отделениях проводился мониторинг клинического состояния ЛЖВ, назначение и мониторинг проведения АРТ. В исследование были включены в том числе «наивные» пациенты, еще не получавшие АРТ. Исследование проводилось в период январь 2017 - июнь 2019 г., в нем участвовало 200 человек, 114 мужчин $(57,0 \%)$ и 86 женщин (43,0\%). Средний возраст пациентов составлял 40,68 $\pm 0,62$ лет (интервал от 29 до 60 лет). Средний возраст мужчин $(40,68 \pm 0,63)$ и женщин $(40,82 \pm 0,63$ года) не различался. Предполагаемый путь инфицирования ВИЧ у $61,5 \%$ пациентов был половой, у $38,5 \%$ - в результате инъекционного потреблении наркотиков. У большинства пациентов (70,9\%) установлена IV стадия ВИЧ-инфекции, III стадия - была у 19,4\%, II - у 4,1\%, I - у 5,6\% ЛЖВ. У всех пациентов была определена дата начала AРТ (или ее отсутствие). Никто из пациентов не получал противопаразитарную терапию до начала исследования. Все пациенты были информированы о конфиденциальности их персональных данных.

Лабораторные исследования включали определение вирусной нагрузки (ВН) ВИЧ и количества CD4 Т клеток. Уровень ВН определяли по количеству РНК-копий ВИЧ-1 в 1 мл плазмы крови. Исследования проводили методом обратной транскрипции и полимеразной цепной реакции (ОТ-ПЦР) с использованием коммерческих тест-систем «Real Time HIV-1» (Abbott). Специфичность тест-системы составляет 99,5\%. Аналитическая чувствительность: верхняя граница концентрации РНК ВИЧ-1 - 10 млн. копий/мл, нижняя граница эквивалентна 40 копиям/мл при исследовании 1 мл образца плазмы. Определение CD4 клеток проводили методом проточной цитометрии с использованием прямой иммунофлюоресценции клеток периферической крови на проточном цитометре FS 500 (Beckman Coulter, CША) с помощью мультипараметрического анализа. Подсчет абсолютного количества CD4 клеток проводили с использованием технологии Flow-Count Fluorespheres.

Биоматериал (фекалии) пациенты собирали во флаконы с консервантом [12] руководствуясь специально разработанными памятками.

Для выявления кишечных паразитов в лаборатории использовали метод концентрации флотацией по Фюлеборну. Исследовали нативные и окрашенные раствором Люголя препараты. Для выявления ооцист криптоспоридий мазки фиксировали смесью Никифорова, высушивали и окрашивали по Циль-Нельсену. Микроскопию проводили под увеличением 10x10-10x100. Статистическую обработку результатов и расчеты проводили с помощью унифицированных функций, предусмотренных программой Microsoft Office Excel.

Результаты исследования. Общая частота выявления кишечных паразитов у ЛЖВ обследованной группы составила 30,0\% (60 из 200). В это число вошли также пациенты, у которых были выявлены не патогенные простейшие (Entamoeba coli и Endolimax nana) - 4 человека и 21 человек, у которых определялись единичные (до 5 в поле зрения) цисты Blastocystis hominis. Паразитарная инвазия (выявление патогенных кишечных паразитов или цист/ооцист условно патогенных кишечных паразитов в количестве более 5 в поле зрения) установлена у 35 пациентов $(17,5 \%)$. У пациентов с паразитарной инвазией чаще всего выявляли Cryptosporidium spp. - у 21 человека (10,5\%), Bl. hominis (более 5 цист в поле зрения) - у 10 пациентов (5,0\%), Ascaris lumbricoides - y 3 (1,5\%), Giardia lamblia - y 1 (0,5\%).

По количеству CD4 T клеток, выделяли пациентов с выраженной (<200 кл/мкл), умеренной (200-349 кл/мкл), средней (350-500 кл/мкл) и незначительной (>500 кл/мкл) 
иммуносупрессией [13]. Среди пациентов, у которых были выявлены кишечные паразиты достоверно чаще $(\mathrm{p}<0,01)$ встречались лица с выраженной иммуносупрессией. Влияние уровня иммуносупрессии на инвазированность ЛЖВ кишечными паразитами представлено на рисунке.

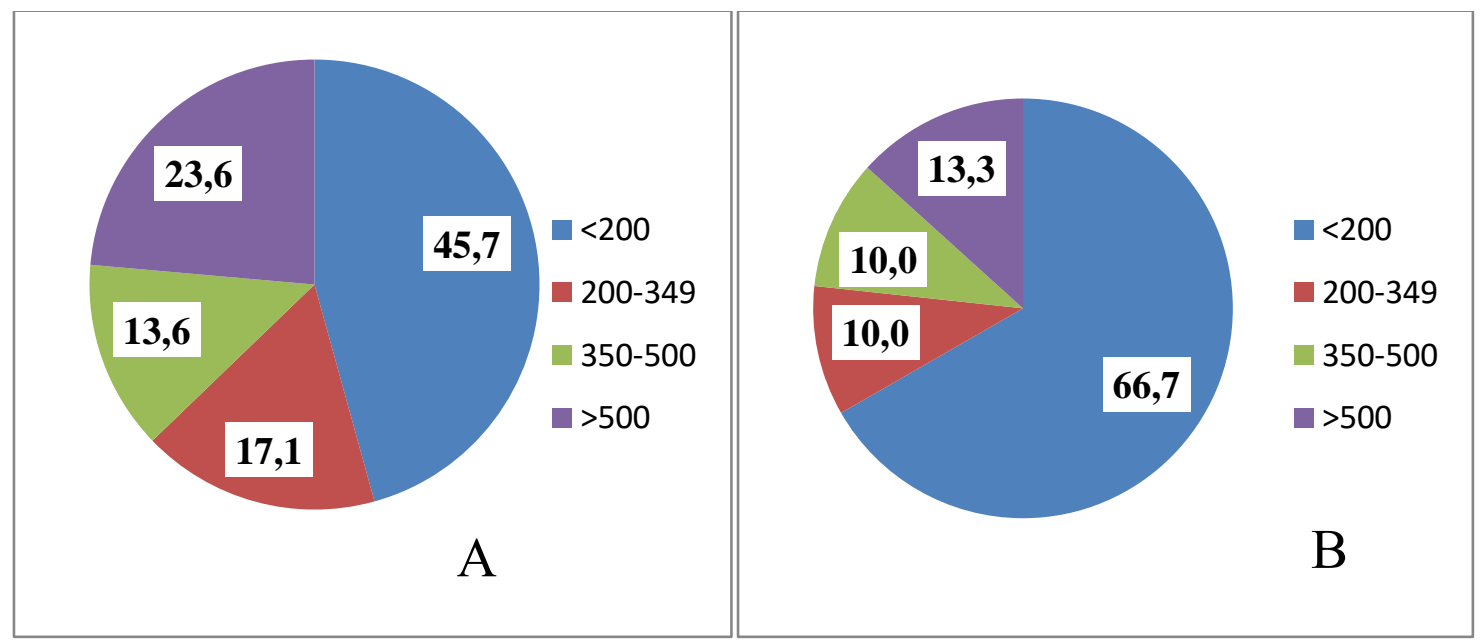

Рис. 1. Распределение ЛЖВ (в \%) с различным уровнем CD4 клеток в зависимости от выявления у них кишечных паразитов. А - кишечные паразиты не выявлены. $B$ - кишечные паразиты выявлены

Среднее количество CD4 клеток у пациентов с паразитарной инвазией составляло $214,09 \pm 38,9$ кл/мкл. В случае выявления у пациентов непатогенных простейших и единичных ооцист Bl. hominis среднее количество CD4 клеток составляло 195,52 $\pm 54,75$ кл/мкл, что было достоверно ниже $(\mathrm{p}<0,05)$, чем у пациентов с отсутствием кишечных паразитов $(329,19 \pm 28,43)$.

Среди ЛЖВ с выявленными кишечными паразитами достоверно реже $(\mathrm{p}<0,01)$ встречались пациенты с неопределяемым уровнем ВН ВИЧ (<40 копий/мл) - 35,0\% (21 из 60), чем среди не инвазированных пациентов - 55,7\% (78 из 140). Таким образом, выявление паразитарной инвазии коррелировало с активностью инфекционного процесса ВИЧ-инфекции.

Среди обследованных ЛЖВ не получали АРТ вообще («наивные пациенты») 84 человека, получали АРТ 116 пациентов, из них терапию до 6 месяцев получали 23 пациента. Среди пациентов, у которых были выявлены кишечные паразиты, АРТ более 6 месяцев получали $28,3 \%$, в группе пациентов, у которых паразиты обнаружены не были - 54,3\% $(\mathrm{p}<0,001)$. «Наивные пациенты» среди ЛЖВ с выявленными кишечными паразитами составили $45,0 \%$ (27 из 60), среди не инвазированных - 35,7\% (50 из 140), p>0,05.

Сравнительная характеристика различных групп обследованных пациентов представлена в таблице.

Таблица 1. Сравнительная характеристика обследованных пациентов в зависимости от выявления кишечных паразитов

\begin{tabular}{|c|c|c|c|c|c|c|c|c|}
\hline \multirow[t]{2}{*}{ Параметры } & \multicolumn{2}{|r|}{$\begin{array}{l}\text { Всего } \\
(200)\end{array}$} & \multicolumn{2}{|c|}{$\begin{array}{c}\text { Не инвазированные } \\
\text { (140) }\end{array}$} & \multicolumn{2}{|c|}{$\begin{array}{c}\text { Паразитарная } \\
\text { инвазия } \\
\text { (35) }\end{array}$} & \multicolumn{2}{|c|}{$\begin{array}{c}\text { Непатогенные } \\
\text { простейшие или } \\
\text { Bl. hominis менше } \\
5 \text { в п/3 (25) }\end{array}$} \\
\hline & $\mathrm{n}$ & $\begin{array}{c}\text { ср.знач } \pm \mathrm{m} \\
\% \pm \mathrm{m}\end{array}$ & $\mathrm{n}$ & $\begin{array}{l}\text { cp.знач } \pm \mathrm{m} \\
\% \pm \mathrm{m}\end{array}$ & $\mathrm{n}$ & $\begin{array}{l}\text { ср.знач } \pm \mathrm{m} \\
\% \pm \mathrm{m}\end{array}$ & $\mathrm{n}$ & $\begin{array}{c}\text { ср.знач } \pm \mathrm{m} \\
\% \pm \mathrm{m}\end{array}$ \\
\hline Мужчины & 114 & 57,0 & 85 & 60,7 & 20 & 57,1 & 11 & 44,0 \\
\hline Женщины & 86 & 43,0 & 55 & 39,3 & 15 & 42,9 & 14 & 56,0 \\
\hline $\begin{array}{l}\text { Средний } \\
\text { возраст }\end{array}$ & \multicolumn{2}{|c|}{$40,68 \pm 0,62$} & \multicolumn{2}{|c|}{$40,74 \pm 0,77$} & \multicolumn{2}{|c|}{$40,17 \pm 1,41$} & \multicolumn{2}{|c|}{$41,84 \pm 1,45$} \\
\hline $\begin{array}{l}\text { Среднее } \\
\text { количество } \\
\text { CD4 кл/мкл }\end{array}$ & \multicolumn{2}{|c|}{$287,35 \pm 22,20$} & \multicolumn{2}{|c|}{$329,19 \pm 28,43$} & \multicolumn{2}{|c|}{$214,09 \pm 38,9 *$} & \multicolumn{2}{|c|}{$172,72 \pm 47,17^{*}$} \\
\hline $\begin{array}{l}\mathrm{BH}<40 \\
\text { копий/мл }\end{array}$ & 101 & $50,5 \pm 3,5$ & 78 & $55,7 \pm 4,2$ & 14 & $40,0 \pm 8,3$ & 7 & $28,0 \pm 9,0^{*}$ \\
\hline $\begin{array}{l}\text { Получают } \\
\text { АРТ меньше } \\
6 \text { месяцев }\end{array}$ & 107 & $53,5 \pm 3,5$ & 64 & $45,7 \pm 4,2$ & 23 & $65,7 \pm 8,0^{*}$ & 20 & $80,0 \pm 8,0 *$ \\
\hline
\end{tabular}

* - разница достоверно отличается от показателей у не инвазированных пациентов 
Обсуждение. Полученные результаты в целом подтверждают данные литературы о высокой распространенности кишечных паразитов у ВИЧ-позитивных пациентов, которая колеблется в пределах $12,6-27 \%$ [14. 15, 16]. Наиболее часто у обследованных нами пациентов были выявлены Cryptosporidium spp. (10,5\%), что также совпадает с результатами, приведенными в систематизированном обзоре, посвященном распространенности Cryptosporidium, Microsporidia и Isospora у ВИЧ-инфицированных лиц [6]. В тоже время, по данным нашего исследования частота выявления у ЛЖВ Giardia lamblia $(0,5 \%)$ и гельминтов $(1,5 \%)$ была невысокой. По нашим данным, инвазированность ЛЖВ Bl. hominis была высокой. Если учитывать пациентов, у которых были выявлены единичные цисты Bl. hominis, распространенность этого условного патогенного простейшего составила $15,5 \%$. Таким образом, установленный нами спектр кишечных паразитов отличался от такового, например, в Эфиопии, где доминировали Ent. histolytica/dispar (18.6\%) и G. lamblia (2.1\%), а общая инвазированость ВИЧ-позитивных лиц составила 26.4\% [17]. Наши данные больше соответствовали результатам, полученным турецкими исследователями [18] при обследовании 65 ВИЧ-позитивных пациентов. Cryptosporidium spp. были выявлены у 21.5\%, Blastocystis spp. - у 10.8\%. Важно также отметить, что спектр кишечных паразитов, выявляемых у ЛЖВ, может не соответствовать значимости той либо другой инвазии для населения региона в целом. Так, нами были получены данные о невысокой распространенности Cryptosporidium spp. у обследованных представителей взрослого населения $(1,1 \%)$, в то же время гельминты были выявлены чаще $(5,2 \%)$, чем у ЛЖВ и представлены не только Ascaris lumbricoides, но и Enterobius vermicularis и Opisthorchis felineus [19].

В нашем исследовании показана достоверная связь между количеством CD4 клеток и наличием кишечных паразитов у ВИЧ-позитивных пациентов. Следует отметить, что в целом в обследованной нами группе ЛЖВ уровень CD4 был меньше 350 кл/мл, что связано с преобладанием среди пациентов лиц с IV стадией ВИЧ-инфекции. При этом среднее количество CD4 T клеток было достоверно ниже в группе пациентов, инвазированных кишечными паразитами. Мы получили данные, указывающие на то, что выявление даже единичных ооцист $\mathrm{Bl}$. hominis у ВИЧ-позитивных лиц может указывать на снижение количества CD4 клеток. Можно предположить, что подходы, которые используются для иммунокомпетентных лиц, в отношении количества выделенных условно патогенных простейших, в частности $\mathrm{Bl}$. Hominis (более 5 в поле зрения), не могут быть использованы для ВИЧ-инфицированных пациентов - выявление даже единичных условно патогенных паразитов у ЛЖВ при наличии клинических проявлений может служить показанием для проведения противопаразитарной терапии. Выявление кишечных паразитов у ЛЖВ также коррелировало с вирусной нагрузкой ВИЧ. Среди лиц с кишечными паразитами достоверно реже встречались пациенты с неопределяемым уровнем копий РНК ВИЧ ( $<40$ копий/мл). Таким образом, выявление у ЛЖВ кишечных простейших, даже условно патогенных, может быть использовано в качестве маркера иммунной супрессии, репликативной активности ВИЧ и, соответственно, коррелировать со стадией ВИЧ-инфекции.

Полученные нами данные согласуются с результатами других исследований о положительном влиянии АРТ на инвазированность кишечными паразитами ВИЧ-позитивных пациентов. Нами не получены достоверные данные о большей распространенности кишечных паразитов у «наивных» пациентов в сравнении с ЛЖВ, которые получают АРТ меньше 6 месяцев. В тоже время инвазированность пациентов, которые получали АРТ больше 6 месяцев, была достоверно ниже $(21,9 \%)$, чем пациентов, которые получали АРТ меньше 6 мес. или не получали вообще - 40,2\%, p $<0,001$. Таким образом положительное влияние АРТ на оппортунистические инфекции и инвазии может быть заметно не ранее, чем через 6 месяцев, после начала АРТ [20, 21].

Заключение. Получены данные о высокой распространенности (30\%) кишечных паразитов у ЛЖВ, обследованных в Киеве (Украина). Инвазия Cryptosporidium spp. составила 10,5\%, Ascaris lumbricoides - 1,5\%, Giardia lamblia - 0,5\%. Условно патогенные простейшие Bl. hominis выявлены у 15,5\% обследованных пациентов. В исследовании показано, что даже обнаружение единичных ооцист Bl. hominis у ЛЖВ может быть косвенным показателем прогрессирования ВИЧ-инфекции, что подтверждает важность паразитологического обследования данной категории пациентов. Основными факторами, связанными с распространенностью кишечных паразитов, были: выраженная иммуносупрессия (<200 CD4 кл/мл), высокий уровень ВН ВИЧ, не получение пациентами АРТ или получение терапии меньше 6 месяцев. 


\section{ЛИТЕРАТУРА}

1. Framm S.R. Soave R. Agents of diarrhea. Med Clin North Am. 1997; 81:427-447.

2. Taye B., Desta K., Ejigu S., Dori G.U. The magnitude and risk factors of intestinal parasitic infection in relation to Human Immunodeficiency Virus infection and immune status, at ALERT Hospital, Addis Ababa, Ethiopia. Parasitol Int. 2014; 63(3): 550-556.

3. Roka M., Goñi P., Rubio E., Clavel A. Intestinal parasites in HIV-seropositive patients in the Continental Region of Equatorial Guinea: its relation with socio-demographic, health and immune systems factors / Trans R. Soc. Trop. Med. Hyg. 2013; 107(8): 502-510.

4. Akinbo F.O., Okaka C.E., Omoregie R. Prevalence of intestinal parasites in relation to CD4 counts and anaemia among HIV-infected patients in Benin City, Edo State, Nigeria Tanzan. J. Health Res. 2011; 13(1): 8-13.

5. Shimelis T., Tassachew Ya., Lambiyo T. Cryptosporidium and other intestinal parasitic infections among HIV patients in southern Ethiopia: significance of improved HIV-related care. Parasit Vectors. 2016;.9:270-277.

6. Wang ZD, Liu Q, Liu HH, Li S, Zhang L, Zhao YK, Zhu XQ. Prevalence of Cryptosporidium, microsporidia and Isospora infection in HIV-infected people: a global systematic review and meta-analysis. Parasit Vectors. 2018 Jan 9;11(1):28.

7. Taye B., Desta K., Ejigu S., Dori G.U. The magnitude and risk factors of intestinal parasitic infection in relation to Human Immunodeficiency Virus infection and immune status, at ALERT Hospital, Addis Ababa, Ethiopia // Parasitol Int. 2014; 63(3):550-600.

8. Missaye A, Dagnew M, Alemu A, Alemu A. Prevalence of intestinal parasites and associated risk factors among HIV/AIDS patients with pre-ART and on-ART attending dessie hospital ART clinic, Northeast Ethiopia. AIDS Res Ther. 2013;10(1): 7-15.

9. Teklemariam Z., Abate D., Mitiku H., Dessie Ya. Prevalence of Intestinal Parasitic Infection among HIV Positive Persons Who Are Naive and on Antiretroviral Treatment in Hiwot Fana Specialized University Hospital, Eastern Ethiopia // ISRN AIDS. 2013. http://dx.doi.org/10.1155/2013/324329

10. Masoumi-As H, Khanaliha K, Bokharaei-Salim F, Esteghamati A, Kalantari S, Hosseinyrad M. Enteric Opportunistic Infection and the Impact of Antiretroviral Therapy among HIV/AIDS Patients from Tehran, Iran. J Public Health. 2019 Apr;48(4):730-739.

11. Nsagha D., Njunda A., Assob N. Intestinal parasitic infections in relation to CD4+ Tcell counts and diarrhea in HIV/AIDS patients with or without antiretroviral therapy in Cameroon. BMC Infectious Diseases. 2016; 16(9): 1-10.

12. Склад для обробки проб досліджуваного матеріалу при проведенні досліджень біологічних матеріалів: патент, Україна № 114976; від 28.08.2017 р. заявл.17.03.2016; опубл.28.08.2017. Бюл.№16.

13. WHO. Interim WHO clinical staging of HVI/AIDS and HIV/AIDS case definitions for surveillance: African Region. World Health Organization; 2005.

14. Silva C.V., Ferreira M.S., Borges A.S., Costa-Cruz J.M. Intestinal parasitic infections in HIV/AIDS patients: experience at a teaching hospital in central Brazil // Scand J Infect Dis. 2005; 37(3): 211-215.

15. Assefa S, Erko B, Medhin G, Assefa Z, Shimelis T. Intestinal parasitic infections in relation to HIV/AIDS status, diarrhea and CD4 T-cell count. BMC Infect Dis. 2009;9:155.

16. Getaneh A, Medhin G, Shimelis T. Cryptosporidium and Strongyloides stercoralis infections among people with and without HIV infection and efficiency of diagnostic methods for Strongyloides in Yirgalem Hospital, southern Ethiopia. BMC Res Notes. 2010;3:90.

17. Gebrewahid T, Gebrekirstos G, Teweldemedhin M, Gebreyesus H, Awala A, Tadla K. Intestinal parasitosis in relation to CD4 count and anemia among ART initiated patients in St. Mary Aksum general hospital, Tigray, Ethiopia. BMC Infect Dis. 2019 Apr 27;19(1):350.

18. Zorbozan O, Quliyeva G, Tunalı V, Özbilgin A, Turgay N, Gökengin AD. Intestinal Protozoa in HivInfected Patients: A Retrospective Analysis. Turkiye Parazitol Derg. 2018 Sep;42(3):187-190.

19. Шагінян В.Р., Данько О.П., Сопіль Г.В., Антоняк С.М., Дяченко О.П. Інвазованість кишковими паразитами ВІЛ-позитивних осіб. Профілактична медицина. 2018; 1(30):91-97.

20. Барлетт Д., Галлант Д. Фам П. Клинические аспекты ВИЧ-инфекции. 2009-2010. М.: Р.Валент, 2010. 490с.

21. HIV 2015/16 www.hivbook.com Edited by Christian Hoffmann and Jürgen K. Rockstroh 